\title{
Impacts of Temperature Gradient on the Intensity of Physical Disturbance and the Water Ecological Biodiversity in the River Estuary
}

\author{
Yan Xu, Yanpeng Cai, Tao Sun, Wen Xu, and Zhifeng Yang
}

\begin{abstract}
In this study, the physical disturbance in the river estuary was discussed as the variation of hydrodynamic fields caused by the human activities. We built the coupled model to forecast the ecological risk with physical disturbance in the different condition of temperature gradient. The temperature gradient was one of the most important parameters to report the growth circumstance of water ecological species, especially for the biodiversity. The relationship between water temperature gradient and the biodiversity was proposed by using the model methods. When the gradient was higher, the biodiversity index was increasing, which was considered as the optimal ecological system.
\end{abstract}

Index Terms-Temperature gradient, physical disturbance, biodiversity, ecological risk, river estuary.

\section{INTRODUCTION}

With the development of human society, more and more high frequent and strength human activities caused the acceleration of emission of greenhouse-effect gas, such as carbon dioxide $\left(\mathrm{CO}_{2}\right)$, nitrous oxide $\left(\mathrm{N}_{2} \mathrm{O}\right)$, methane $\left(\mathrm{CH}_{4}\right)$ and hydrochlorofluorocarbon (HFCs), this phenomenon called greenhouse effect would lead to the climate change on earth [1]-[4]. Climate change had the direct impact of water temperature value. According to some study on the long-term detection of regime and fluctuation of water temperature in local areas, the annual surface temperature would grow from the present value of $20.4 \mathrm{C}$ to $21.5 \mathrm{C}$ in 2030 to 2050 and to $23.2^{\circ} \mathrm{C}$ in 2070 to $2090( \pm 0.25 \%)$ for the open water reservoirs and water resources in Australia [5]; The area of Mediterranean temperature had increased in the period 2071-2100 compared to 1990-2019. The assessed temperature had changed of partly more than $4^{\circ} \mathrm{C}$ by the end of this century [6]. Additionally, some natural reasons such as geological evolution, chemical reaction, natural evaporation, concentration of mixtures, soil structure and ecological biodiversity could impact the water thermal balance. In short, the thermal disturbance caused by climate change would have huge influence of water ecological system balance, which could be damaged or destroyed by the sustainability of thermal disturbance.

Water temperature was one of the most significant factors

Manuscript received May 20, 2015; revised September 18, 2015. This work was supported in part by the School of Environment, Beijing Normal University, China.

The authors are with the School of Environment, Beijing Normal University, China (e-mail: grawain007@163.com, yanpeng.cai@bnu.edu.cn). involved not only on the designation of engineering project, and had the relationship with irrigation, industry and landscape [7]. Water temperature as one parameter on the hydrology and flow physics also could report the water thermal disturbance form natural and artificial factors directly. In the natural lake and river, the temperature was also had the function to response the health and the range of risk for water ecological systems, which could determine the growth stability of species and the biodiversity for eco-system [8], [9], [10]. Many engineering scholars had research the thermal disturbance on the hydraulic construction and reservoir scheduling. On the other hand, the ecological scientists tried to find the inner mechanism for species and the systems. For micro-zooplankton in the deep water, the capture rate was high at the $8-16^{\circ} \mathrm{C}$ degree [11]; the much warm temperatures $(16.81 \pm 0.05 \mathrm{C})$ experienced higher growth for barnacle growth compared to the $13.67^{\circ} \mathrm{C}$ [12]. In the ocean or the coastal areas, the water temperature could impact the ecological performance, the high temperatures (about 25-30 C) increased mortality of marine species and lowered both photosynthetic rate and growth rate [13]. On the other hand, many studies had demonstrated that human activities and climate change had impact on water temperatures [14], [15]. Some human activities such as coastal reclamation could change the thermal balance and destroy the suitable temperature structures in the water body [16], [17].

In general modeling study, the thermal structure and heat transfer of water body was becoming more important for ecological models in order to account for the effects of coastal reclamation and other human activities. Therefore, the thermal structure in the water body should be simulated accurate and we could find the inner hydrodynamics to reveal the water ecological process. Some different kinds of freshwater plant in the same climate conditions had the optimal growth temperature for their living respectively [18]. The shoot mortality of eelgrass (Zostera marina L.) was generally low at water temperatures between 5 and $20 \mathrm{C}$. High temperatures (i.e. above $20 \mathrm{C}$ ) stimulated, however, shoot mortality and the highest mortality $(55.6 \pm 14.2 \%)$ was observed at $30^{\circ} \mathrm{C}$. Water temperature had a strong effect on the production of new leaves and leaf elongation rate. The highest rate of leaf production was found at $20^{\circ} \mathrm{C}(3.76 \pm 0.35)$ and the lowest at $5 \mathrm{C}(1.25 \pm 0.25$ leaves produced) [19]. The seawater temperature also affected the distribution and morphology of marine benthic community [20]. The juvenile specimens of marginal marine species (Rosalina globularis) were observed that the optimal growth temperature was $30 \mathrm{C}$; the thermal stratification in the lake or reservoir could affect 
the growth situations of microorganism [21].

Since evolution of river channel and the effect of coastal erosion, the ecological system often had the feature of vulnerability and instability in the region of river estuary. In addition, many estuary areas had high intensity of human activities-harbor construction, land reclamation and resource exploitation, which caused the natural ecological environment facing many dangerous and potential risks [22], [23]. It was necessary to study the ecological risk under the thermal disturbance in the estuary area. Based on the optimal growth temperature, the ecological thermal threshold could be discussed the intensity of ecological risk.

However, the study of optimal growth temperature for water ecological species were ignored the impact factor of hydrodynamics, especially the special conditions of flow fields. The main purpose of this study was to assess the thermal structures impact the water ecological species at the condition of density currents. We were using the numerical simulation to assess the optimal areas for species growth. The species was selected the indicator of river estuary.

\section{MATERIALS AND METHODS}

\section{A. The Background Theory and Methods}

In the nature, the water temperature determined the water ecological structure and the stability [24]. The thermal transfer had some energy sources form the external environment (Fig. 1) [25]. Firstly, the solar radiation entered into the water body experiencing the attenuation to change the water temperature through heat exchange, which was the main energy sources of water temperature; secondly, the water body had the heat transfer process to vary the water temperature; on the other hand, the evaporation would release the total energy of water to alter the temperature. In this article we ignored the process of energy loss to the external environment; the solar energy input to the system was steady; the thermal dynamics was the simple course of inner heat transfer. The water temperature was the only arithmetic solution was exporting to the energy equation. We had simulated the 5 degree of temperature gradient $(0.25 \mathrm{C}$, $0.50 \mathrm{C}, 1.00 \mathrm{C}, 2.00^{\circ} \mathrm{C}$ and $4.00 \mathrm{C}$ ) to simulate the vertical thermal structure in realistic environment, then marked the working condition as I, II, III, IV, V.

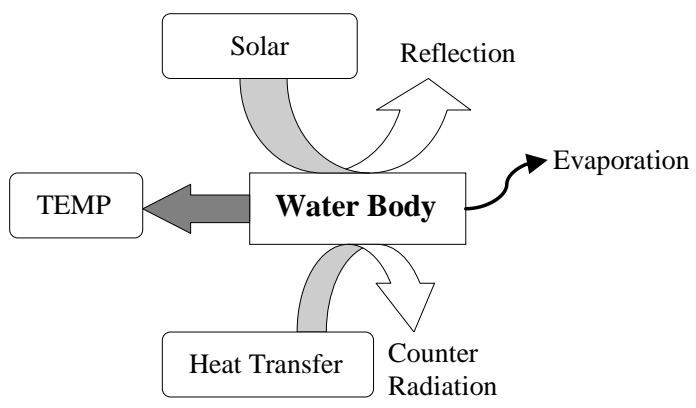

Fig. 1. Thermal balance of water body.

In the river estuary, the special ecological species made up the whole ecological system. The different species had different optimal temperature to maintain the maximum biomass for growth. Several typical species survived in the river estuary was listed at the Table I below, and according to some biological physiology researches, the optimal growth temperature for species could be list as the ecological threshold value range [26]-[31].

TABLE I: THE OPTIMAL GROWTH TEMPERATURE FOR TYPICAL SPECIES IN RIVER ESTUARY

\begin{tabular}{c|ccc}
\hline $\begin{array}{c}\text { Functional } \\
\text { group }\end{array}$ & $\begin{array}{c}\text { Species } \\
\text { common } \\
\text { name }\end{array}$ & Scientific name & $\begin{array}{c}\text { Range of } \\
\text { optimal growth } \\
\text { temperature }\end{array}$ \\
\hline Phytoplankton & Green algae & $\begin{array}{c}\text { Microcystis } \\
\text { aeruginosa } \\
\text { Skeletonema } \\
\text { costatum } \\
\text { Znoflagellate }\end{array}$ & $24 \sim 26^{\circ} \mathrm{C}$ \\
Zoobenthos & Diatom & $\begin{array}{c}\text { Prontrum } \\
\text { minimum } \\
\text { Penaeus }\end{array}$ & $23.87 \pm 0.44^{\circ} \mathrm{C}$ \\
Plant (in \\
average)
\end{tabular}

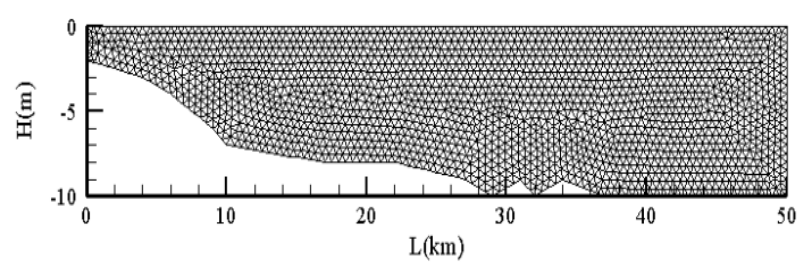

Fig. 2. The calculation girds.

TABLE II: THE BACKGROUND DATA IN THE ACTUAL ENVIRONMENT

\begin{tabular}{c|ccccc}
\hline Factors & $\begin{array}{c}\text { Temp } \\
\text { at water } \\
\text { surface }\end{array}$ & Wind & $\begin{array}{c}\text { Inflow } \\
\text { velocity }\end{array}$ & $\begin{array}{c}\text { Water } \\
\text { depth }\end{array}$ & $\begin{array}{c}\text { Source } \\
\text { term }\end{array}$ \\
\hline Value & $28^{\circ} \mathrm{C}$ & $1 \mathrm{~m} / \mathrm{s}$ & $0.8 \mathrm{~m} / \mathrm{s}$ & $10 \mathrm{~m}$ & $258 \mathrm{~W} / \mathrm{m}^{2}$ \\
\hline
\end{tabular}

We were using the three sorts of water phytoplankton (Microcystis aeruginosa, Skeletonema costatum and Prorocentrum minimum), which were the typical species growing in the offshore sea or freshwater, having the possibility of potential ecological risk to cause the red tide or incident of pollution in the coastal and river estuary areas to compare the range of optimal growth temperature. In addition, the two kinds of zoobenthos (Penaeus orientalis and Tegillarca granosa) and two species of aquatic plant (Phragmites australis and Elodea canadensis) were list in the Table I to react the ecological response for different functional groups. Because the all parts of plant had different adaptability to temperature, the mean value was selected.

Through the simulation process, the coupled hydrodynamics and ecological model could be built to research the ecological response under the thermal disturbance. We ignored the other factors, such as water quality, meteorological fluctuation, the inner mechanism for temperature dynamics was to be revealed in this article. The background environment to be selected was the Yellow River estuary, which was one of the most typical, youngest and recently active estuary areas in China, Shandong province, which was located in the warm temperate semi-humid continental monsoon climate zone-between the south of Bohai Bay and western part of Laizhou Bay $\left(36^{\circ} 55^{\prime} \sim 38^{\circ} 16^{\prime} \mathrm{N}\right.$, $\left.117^{\circ} 31^{\prime} \sim 119^{\circ} 18^{\prime} \mathrm{E}\right)$. The estuary was influenced by Pacific 
Ocean and Eurasia, with a high precipitation $(530 \mathrm{~mm} \sim 630 \mathrm{~mm})$ in summer, enjoying a wild climate and four distinctive seasons. There had built the national natural and ecological reservation (about $1500 \mathrm{~km}^{2}$ ) since 1992 . We had collected the meteorological monthly data in the summer of 2009, and the related environmental parameters were shown in the Table II. The vertical underwater data from the river estuary to the coastal areas (about $50 \mathrm{~km}$ ) to simulate the water hydrodynamics process, the computational gird as shown in Fig. 2.

\section{B. The Hydrodynamics Model}

In the estuary, the sediment was one of the most important problems, especially in the basin of Yellow river estuary, which had the biggest sediment discharge in China. To simulate the sediment, the multiphase flow model should be used to calculate the variation of flow. Therefore, we chose the Eulerian model and the general equation as follow:

$$
\frac{\partial}{\partial t}\left(\alpha_{q} \rho_{q}\right)+\nabla \cdot\left(\alpha_{q} \rho_{q} v_{q}\right)=\sum_{p=1}^{n}\left(m_{p q}-m_{q p}\right)
$$

where $v_{q}$ is the velocity of phase $q$ and $m_{p q}$ is the mass transfer form the phase-p to phase-q; $m_{p q}$ is the mass transfer from the phase-q to phase-p; the $a_{q}$ is defined as the volume fraction for phase-q.

On the other hand, the RNG $k-\varepsilon$ transport equation was written as follows to simulate the turbulent [32].

$$
\begin{aligned}
& \frac{\partial}{\partial t}(\rho k)+\frac{\partial}{\partial x_{i}}\left(\rho k u_{i}\right)=\frac{\partial}{\partial x_{j}}\left(a_{k} \mu_{e f f} \frac{\partial k}{\partial x_{j}}\right) \\
& +G_{k}+G_{b}-\rho \varepsilon-Y_{M}+S_{k} \\
& \frac{\partial}{\partial t}(\rho \varepsilon)+\frac{\partial}{\partial x_{i}}\left(\rho \varepsilon u_{i}\right)=\frac{\partial}{\partial x_{j}}\left(a_{\varepsilon} \mu_{e f f} \frac{\partial \varepsilon}{\partial x_{j}}\right) \\
& +G_{1 \varepsilon} \frac{\varepsilon}{k}\left(G_{k}+C_{3 \varepsilon} G_{b}\right)-C_{2 \varepsilon} \rho \frac{\varepsilon^{2}}{k}-R_{\varepsilon}+S_{\varepsilon}
\end{aligned}
$$

In the equations, $G_{k}$ represents the generation of turbulence kinetic energy due to the mean velocity gradients; $G_{b}$ is the generation of turbulence kinetic energy due to buoyancy; $Y_{M}$ is the contribution of the fluctuating dilatation in compressible turbulence to the overall dissipation rate; $a_{k}$ and $a_{\varepsilon}$ are the inverse effective Prandtl numbers for $k$ and $\varepsilon$, repectively. $S_{k}$ and $S_{\varepsilon}$ are source terms.

To simulate the temperature dynamics, the basal energy equations should be selected, the basic equations as follow:

$$
\begin{gathered}
\frac{\partial}{\partial t}(\rho \mathrm{E})+\nabla \cdot(\vec{v}(\rho \mathrm{E}+p))=\nabla \cdot\left(k_{e f f} \cdot \nabla T\right. \\
\left.-\sum_{j} h_{j} \vec{J}_{j}+\left(\bar{\tau}_{e f f} \cdot \vec{v}\right)\right)+S_{h} \\
E=h-\frac{p}{\rho}+\frac{v^{2}}{2}
\end{gathered}
$$

where $h$ was the value of enthalpy, $K_{\text {eff }}$ was the effective thermal conductivity; $\tau_{\text {eff }}$ was the effective stress tensor; and the $S_{h}$ was the energy source term.

\section{Case Conditions and Parameters Calibration}

The no slip wall boundary condition was described as the boundary condition in the bottom and top of water body, which had the adiabatic status. The first phase was the water body and the water density was following the fitting equation of water temperature:

$$
\rho=-0.005635 T^{2}+3.100714 T+573.52974
$$

The inlet water was the second phase which was the mixture fluid consisting of pure water and fine sediment particles. Furthermore, we picked quartz sand as the major constituent for mixture currents, which density was $1650 \mathrm{~kg} / \mathrm{m}^{3}$. The density of mixture currents could be calculated from the equation of relationship between solution and solute. As the result, the density of mixture currents was $1046.78 \mathrm{~kg} / \mathrm{m}^{3}$. The initial velocity of sediment water was $0.8 \mathrm{~m} / \mathrm{s}$. Other parameters as followed in Table III.

TABLE III: THE CALIBRATION OF RELEVANT PARAMETERS

\begin{tabular}{c|ccc}
\hline Parameters & Unit & Value & Description \\
\hline$\alpha_{\varepsilon}$ & & 0.75 & prandtl Number \\
$\rho_{q}$ & $\mathrm{Kg} / \mathrm{m}^{3}$ & 1046.78 & mixture water density \\
$v$ & $\mathrm{Kg} / \mathrm{ms}$ & 0.001003 & water viscosity \\
$v_{q}$ & $\mathrm{Kg} / \mathrm{ms}$ & 0.00302 & mixture water viscosity \\
$d$ & $\mathrm{~mm}$ & 0.001 & particle diameter \\
$n_{\text {top }}$ & & 0.0001 & roughness in top surface \\
$n_{\text {bottom }}$ & & 0.0003 & roughness in bottom \\
$\tau_{\text {eff }}$ & $\mathrm{N} / \mathrm{m}^{2}$ & 8.35 & surface \\
$K_{\text {eff }}$ & & 0.866 & effective stress tensor \\
$C_{2 \varepsilon}$ & & 1.68 & conductivity \\
$C_{3 \varepsilon}$ & & 1.42 & constant \\
\end{tabular}

\section{RESUlt AND DisCUSSION}

\section{A. The Effect of Physical Fields}

The different temperature gradient was causing the thermal variation in the water body. The effect of hydrodynamics was intuitive revealed by the contours. The turbulent intensity, which was one physical quantity to characterize the physical disturbance for fluid, could report the disturbance situations under different temperature gradient. The distribution of turbulent intensity in the condition of high and low value of temperature gradient was shown in Fig. 3.

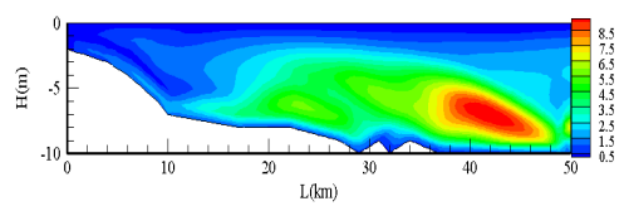

a) The temperature gradient was $0.25^{\circ} \mathrm{C}$.

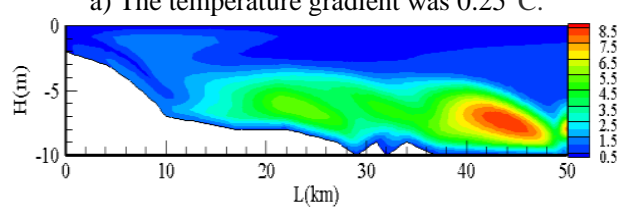

b) The temperature gradient was $4.00^{\circ} \mathrm{C}$ Fig. 3. The distribution of turbulent intensity. 
When the water flow was stabilized by elapsing the flow time, the distribution of turbulent intensity had some differentiations. With the decreasing of temperature gradient, the area of the regions, where the value of turbulent intensity $\geqslant 5.5$, was much larger than the condition of high temperature gradient. The thermal disturbance was introducing the physical perturbation of water dynamics. Compared to the two different conditions from Fig. 3, the regions (the intensity was greater than 5.5) proportion of the total dimension was $77.1 \%$ and $69.3 \%$ respectively. In other words, the strength of current disturbance caused by the difference of thermal structure was increased by $7.8 \%$. In addition, When the temperature gradient was $0.25^{\circ} \mathrm{C}$, the strongest areas of turbulent intensity had the scope of length $L_{0.25} \in[37,48)$; In the same situation, when the temperature gradient was $4.00^{\circ} \mathrm{C}$, the strongest areas of turbulent intensity had the scope of length $L_{4} \in[40,48)$. With the increasing of temperature gradient, the scope of turbulent disturbance was getting much narrower. Therefore, the intensity of flow disturbance got much lower than the working condition of low temperature gradient (I).

\section{B. The Effect of Water Ecological Fields}

On the other hand, the area ratio of suitable growth temperature regions was able to be found by analyzing the optimal growth temperature for the ecological species based on the physical and hydraulic result. The distribution of optimal growth for water species was shown in Table IV (the scientific name was shortening as the first letter).

The rational hypothesis was proposed that the biomass of each species was homogeneous in the unit area. Then the probability of individual optimal survival for each species was similar with the area ratio of the optimal growth temperature numerically. Therefore, by analyzing from the Table IV, the suitable growth condition for each species was revealed. When the temperature gradient was high, the total number of growth rate was above the $1 \%$, which was defined a minimum threshold of optimal survival species in the external circumstance. Because of the reduction of water temperature gradient, the mean temperature difference was decreased, causing the cut of optimal temperature range satisfying the water species. This phenomenon had been explaining the reason why the biodiversity was cut down in the situation of small temperature gradient from the perspective of thermodynamics. In addition, since the range of optimal growth temperature was fluctuated in $28^{\circ} \mathrm{C}$, which was a critical point focused on the environmental water temperature in the condition of low temperature gradient, the area ratio for species of Penaeus orientalis and Phragmites australis were very high at the condition I. From another point of view, the range of optimal growth temperature got much wider, the rate of survivability for water species got much higher.

The condition of the total number of growth rate $\geqslant 1 \%$ could be described as the low risk for the particular water ecological species, the ecological risk for the growth of water species as shown in the Table V. The increasing of temperature gradient had brought about the effect that was enhancing the sort of optimal survival of water ecological species. In order to quantitative analysis of the results, the biodiversity index had been introduced to study the relationship between thermal structure and the water ecological biodiversity.

According to the Shannon-Winner equation, the biodiversity index could be calculated to describe the health of ecological system in river estuary.

$$
H^{\prime}=-\sum_{i=1}^{r} P_{i} \operatorname{Ln} P_{i}
$$

where $H^{\prime}$ was the index of ecological biodiversity, $P_{i}$ was the proportional abundance of species $i$, and $r$ was the total number of species.

TABLE IV: THE AREA RATIO UNDER THE OPTIMAL GROWTH TEMPERATURE

\begin{tabular}{c|ccccc}
\hline & $I$ & $I I$ & $I I I$ & $I V$ & $V$ \\
\hline M. A. & 0.58 & 1.20 & 87.12 & 89.35 & 89.91 \\
S.C. & 0 & 0.08 & 0.25 & 0.76 & 1.35 \\
P. . & 0 & 0.01 & 0.12 & 1.27 & 1.97 \\
P. $O$. & 100 & 95.23 & 92.07 & 90.50 & 83.33 \\
T. $G$. & 0.58 & 32.76 & 53.28 & 69.91 & 80.24 \\
P. A. & 100 & 98.72 & 90.35 & 89.31 & 82.20 \\
E. C. & 0 & 0.23 & 1.33 & 65.02 & 87.23 \\
$H^{\prime}$ & 0.092 & 0.100 & 0.143 & 0.177 & 0.187 \\
\hline \multicolumn{7}{r}{}
\end{tabular}

TABLE V: THE ECOLOGICAL RISK OF OPTIMAL GROWTH FOR SPECIES IN DIFFERENT CONDITION

\begin{tabular}{c|ccccc}
\hline & $I$ & $I I$ & $I I I$ & $I V$ & $V$ \\
\hline M. A. & - & + & + & + & + \\
$S . C$. & - & - & - & - & + \\
$P . M$. & - & - & - & + & + \\
$P . O$. & + & + & + & + & + \\
$T . G$. & - & + & + & + & + \\
$P . A$. & + & + & + & + & + \\
$E . C$. & - & - & + & + & + \\
\hline
\end{tabular}

The internal ecological mechanism with thermal dynamics could be discovered by calculating the Shannon-Winner biodiversity index. As shown in the Fig. 4, the variation of the water ecological biodiversity index with the vertical water temperature gradient could be displayed. With the increasing of water temperature gradient, the Shannon index was growing up either, and the growth rate was about $2.5 \% \pm 0.02$.

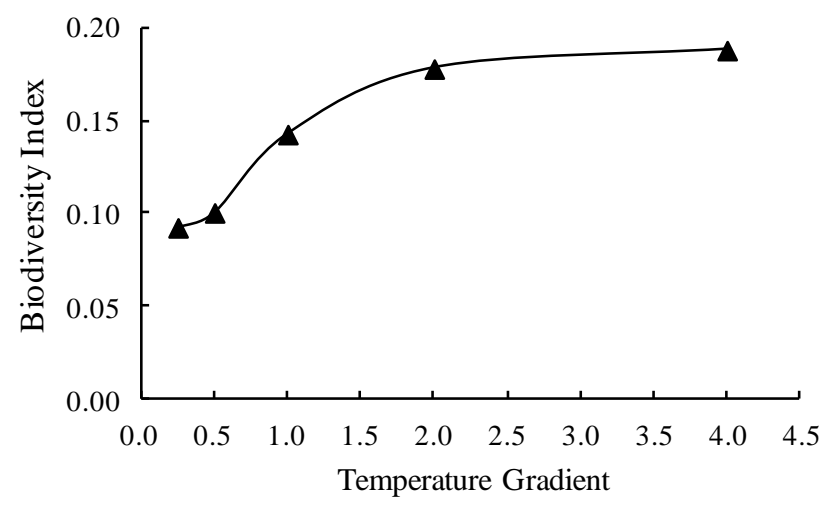

Fig. 4. The variation of biodiversity index with temperature gradient.

\section{CONCLUSIONS}

The vertical thermal structure, which was characterized specifically by the vertical temperature gradient, had an influential effect on water ecological and physical processes. The intensity of flow disturbance was getting stronger with the decreasing of water temperature gradient. Under the condition of high degree of turbulent currents (the temperature gradient was $0.25^{\circ} \mathrm{C}$ ), the scope of length with 
the strongest areas of turbulent intensity was getting much larger, and the water ecological biodiversity index was getting much lower in the view of ecological fields, which the value of biodiversity index was 2 . However, the condition of low degree of turbulent currents (the temperature gradient was $4.00^{\circ} \mathrm{C}$ ) had the states adversely, which the value of Shannon-Winner was 4.

In the research, the process of building numerical model still had some shortages, the impacts of external short wave solar radiation, evaporation, water quality and the water depth. The reasonable assumptions made the complicated problem much simpler. In the future study, we would take advantage of the modeling method and add some other environmental factors to make the predigested model much more perplexed. The prefect model coupled ecological and hydrodynamics should be created to reveal the inner regulation between physical and water ecological fields.

\section{ACKNOWLEDGMENT}

This study was supported by the program of "Aquatic environment, water ecology and comprehensive management of river basin" and the Major Project of Chinese National Programs for Fundamental Research and Development (2013CB430402).

This study has been supported by the National Science Foundation for Innovative Research Group (No. 51121003)

\section{REFERENCES}

[1] J. Lyons, J. S. Stewart, and M. Mitro, "Predicted effects of climate warming on the distribution of 50 stream fishes in Wisconsin, USA," Journal of Fish Biology, vol. 77, no. 8, pp. 1867-1898, Nov. 2010.

[2] S. R. William, "Simulating the effect of climate change on stream temperature in the Trout Lake Watershed, Wisconsin," Science of the Total Environment, vol. 521, pp. 11-18, July 2015.

[3] V. Vliet, T. H. Michelle et al., "Global river discharge and water temperature under climate change," Global Environmental Change, vol. 23, no. 2, pp. 450-464, April 2013.

[4] D. R. Feldman et al., "Observational determination of surface radiative forcing by CO2 from 2000 to 2010," Nature, vol. 519, no. 7543, pp. 339-343, June 2015

[5] H. Fernanda, C. Lemckert, and H. Zhang, "Impacts of climate change on temperature and evaporation from a large reservoir in Australia," Journal of Hydrology, vol. 475, pp. 365-378, Dec. 2012.

[6] H. Elke and J. Jacobeit, "Downscaling future climate change: Temperature scenarios for the Mediterranean area," Global and Planetary Change, vol. 63, no. 2, pp. 127-131, Sep. 2008.

[7] S. J. Zhang and W. Q. Peng, "Water temperature structure and influencing factors in Ertan Reservoir," Journal of Hydraulic Engineering, vol. 40, no. 10, pp. 1254-1258, Oct. 2009.

[8] X.-P. Kong and S.-H. Ye, "The impact of water temperature on water quality indexes in north of Liaodong Bay," Marine Pollution Bulletin, vol. 80, no. 1, pp. 245-249, March 2014.

[9] S. Victor and S. Nicol, "Polar ocean ecosystems in a changing world," Nature, vol. 437, no. 7057, pp. 362-368, Sep. 2005.

[10] P. Adília et al., "The effects of water acidification, temperature and salinity on the regenerative capacity of the polychaete Diopatra neapolitana," Marine Environmental Research, vol. 106, pp. 30-41, May 2015

[11] G. Andrea et al., "The influence of flow velocity and temperature on zooplankton capture rates by the cold-water coral Dendrophyllia cornigera," Journal of Experimental Marine Biology and Ecology, vol. 466, pp. 92-97, May 2015.

[12] Nishizaki, T. Michael, and E. Carrington, "The effect of water temperature and velocity on barnacle growth: Quantifying the impact of multiple environmental stressors," Journal of Thermal Biology, vol. 10, pp. 1-10, Feb. 2015.

[13] Nejrup, L. Brammer, and M. F. Pedersen, "Effects of salinity and water temperature on the ecological performance of Zostera marina," Aquatic Botany, vol. 88, no.3, pp. 239-246, April 2008.
[14] S. Philipp and S. J. Hook, "Space observations of inland water bodies show rapid surface warming since 1985," Geophysical Research Letters, vol. 37, no. 22, pp. 1-5, Nov. 2010.

[15] G. Piero et al., "Ecological effects of multiple stressors on a deep lake (Lago Maggiore, Italy) integrating neo and palaeolimnological approaches," Journal of Limnology, vol. 71, no. 1, p. e1, Jan. 2012.

[16] M. Y. E. Sayed, "Environmental impacts of dredging and land reclamation at Abu Qir Bay, Egypt," Ain Shams Engineering Journal, vol. 3, no. 1, pp. 1-15, March 2012.

[17] Z. Q. Xie et al., "Accelerated human activities affecting the spatial pattern of temperature in the Yangtze River delta," Quaternary International, vol. 226, no. 1, pp. 112-121, Oct. 2010.

[18] R. Tenna et al., "Growth and morphology in relation to temperature and light availability during the establishment of three invasive aquatic plant species," Aquatic Botany, vol. 102, pp. 56-64, Oct. 2012.

[19] Nejrup, L. Brammer, and M. F. Pedersen, "Effects of salinity and water temperature on the ecological performance of Zostera marina," Aquatic Botany, vol. 88, no. 3, pp. 239-246, April 2008.

[20] R. Nigam et al., "Response of benthic foraminifera Rosalina leei to different temperature and salinity, under laboratory culture experiment," Journal of the Marine Biological Association of the UK, vol. 88, no. 4, pp. 699-704, June 2008.

[21] J.-P. Debenay et al., "Water stratification in coastal lagoons: Its influence on foraminiferal assemblages in two Brazilian lagoons," Marine Micropaleontology, vol. 35, no. 1, pp. 67-89, Nov. 1998.

[22] C. M. Jason et al., "Avian ecological risk potential in an urbanized estuary: Lower Hackensack River, New Jersey, USA," Science of the Total Environment, vol. 407, no. 3, pp. 1035-1047, Jan. 2009.

[23] P. Shitao. (April 2015). The nutrient, total petroleum hydrocarbon and heavy metal contents in the seawater of Bohai Bay, China: Temporal-spatial variations, sources, pollution statuses, and ecological risks. Marine Pollution Bulletin. [Online]. 10. pp. 1-7. Available: http://doi:10.1016/j.marpolbul.2015.03.032

[24] H. Jochem, D. Eppel, and F. Tanzer, "Analysis of thermal impact in tidal rivers and estuaries," Water Research, vol. 14, no. 10, pp. 1409-1419, April 1980.

[25] C.M. Bayani et al., "Analysis of the temperature dynamics of a proglacial river using time-lapse thermal imaging and energy balance modeling," Journal of Hydrology, vol. 519, pp. 1963-1973, Nov. 2014.

[26] Z.-S. Chu et al., "The effect of temperature on growth characteristics and competitions of Microcystis aeruginosa and Oscillatoria mougeotii in a shallow, eutrophic lake simulator system," Eutrophication of Shallow Lakes with Special Reference to Lake Taihu, Springer Netherlands, pp. 217-223, 2007.

[27] X. Ning et al., "Effects of temperature, salinity and irradiance on the growth of the harmful dinoflagellate Prorocentrum donghaiense Lu," Harmful Algae, vol. 9, no. 1, pp. 13-17, Jan. 2010.

[28] F. G. Paul, "The adenylate energy charge in marine phytoplantkon: The effect of temperature on the physiological state of Skeletonema costatum (Grev.) Cleve," Journal of Experimental Marine Biology and Ecology, vol. 27, no. 1, pp. 37-45, April 1977.

[29] M. G. Johnson and R. O. Brinkhurst, "Production of benthic macroinvertebrates of Bay of Quinte and Lake Ontario," Journal of the Fisheries Board of Canada, vol. 28, no. 11, pp. 1699-1714, April 1971.

[30] M. Sha and S. Tu, "Modeling thermal effect on growth of Chinese shrimp, Penaeus chinensis (Osbeck)," Ecological Modeling, vol. 80, no. 2, pp. 187-196, July 1995.

[31] R. Tenna et al., "Growth and morphology in relation to temperature and light availability during the establishment of three invasive aquatic plant species," Aquatic Botany, vol. 102, pp. 56-64, Oct. 2012.

[32] Ansys Fluent Theory Guide, Ansys Inc., 2011.

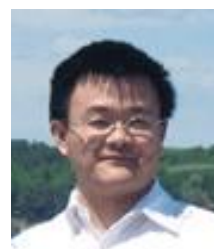

Yanpeng Cai was born in Sichuan, China in January, 1978. He obtained a bachelor degree at Beijing Normal University, China in 2000. He graduated with a master's degree in environmental science and engineering in his alma mater in 2003. Then, he successfully got the doctor's degree in environmental systems engineering. In 2013, he went back to China with the honor of "Thousand Talents program". Now he is a professor in the School of Environment, Beijing Normal University, China. His research interests cover integrated non-point source pollution management, environmental decision-making under uncertainty, ecological remediation, and sustainable development. 


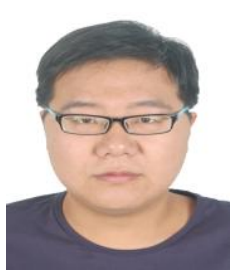

Yan Xu was born in Shanxi, China on January 12 1989. He obtained a master degree of municipal engineering from Xi'an University of Architecture and Technology, Xi'an, China in 2014, and the main research fields were the municipal engineering and the source water treatment engineering. Now, he is studying in the Beijing Normal University, Beijing, China for earning his $\mathrm{Ph} . \mathrm{D}$. degree in environmental science form School of Environment, Beijing, China. His main research interest is the simulation and management of ecological process under the condition of coastal reclamation. Currently, he has published three papers about environmental simulation in domestic and international journals.

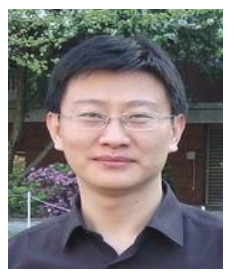

Tao Sun was born in Xinjiang, China in 1975. He obtained a bachelor degree in College of Hydraulic and Civil Engineering in Xinjiang Agriculture University, China in 1996. He graduated with a master's degree in the College of Hydraulic and Civil Engineering, Xinjiang Agriculture University, China in 1999. Then, he went further study in Tianjin University, China. In 2004, he went to School of Environment, Beijing Normal University, China. Now he is a professor in the School of Environment, Beijing Normal University, China. His research interests cover water ecological process simulation, management of water resources.

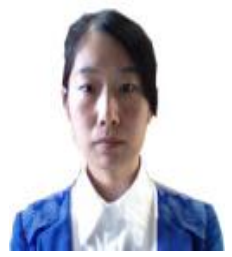

Wen Xu was born in Hubei, China on July 1, 1989 She obtained a bachelor degree in groundwater science and engineering from the School of Environmental Science, China University of Geosciences (Wuhan) in 2011. In September the same year, she went further study in her alma mater, and the main research fields were groundwater pollution and protection, and environmental isotope tracing. In 2014, she graduated with a master's degree in groundwater science and engineering. Now, she is a $\mathrm{Ph} . \mathrm{D}$. student at the School of Environment, Beijing Normal University. Her main research interest is the monitoring and management of reactive nitrogen in agriculture soils and groundwater environment. Currently, she has published two papers about isotopic analytical and application in domestic and international journals.

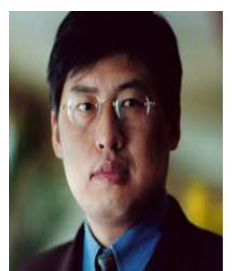

Zhifeng Yang was born in Hebei, China in 1963. He obtained a bachelor degree in Hebei Agricultural University, China in 1982. He graduated with a master's degree in Dalian University of Technology in 1986. In the year 1989, he successfully got his doctor's degree. Now he is the dean and a distinguished professor in the School of Environment, Beijing Normal University. His research interests cover water resource management, water quality simulation, environment system engineering, and sustainable development. 